\title{
活性炭によるハロカーボン類の気相吸着平衡 ${ }^{\dagger}$
}

\author{
富澤＼cjkstart猛・永川ゆう子・有田浩二
}

\author{
松下電器産業（株）生活システム研究センター
}

\begin{abstract}
4 種類のハロカーボン, ジクロロジフルオロメタン (CFC-12), クロロジフルオロメタ ン(HCFC-22)，1，2- ジクロロ-1，1，2，2， - テトラフルオロエタン (CFC-114)，ブロモト リフルオロメタン (halon-1301) に対する活性炭の吸着平衡を測定した。測定值は Dubinin-Astakhov 式: $\boldsymbol{W}=\boldsymbol{W}_{0} \exp \left\{-(\boldsymbol{A} / \boldsymbol{E})^{n}\right\}$ にしたがって整理し, 同式の各パラメー タを決定した。得られたパラメータを用いた計算值と測定值とは良く一致した。 $n$ 值は吸 着剂と吸着質との各種組み合わせで $1.2 \sim 2.5$ の範囲にあり, 吸着空間の極限容積 $W_{0}$ は, 同一の吸着剂に対して吸着質の種類にかかわらずほぼ一定の值となった．特性エネルギー $E$ および $n$ 值と吸着質分子径との間には，良好な相関関係が認められた.
\end{abstract}

\section{緒言}

大気中に放散されたある種のハロカーボン（ハロゲン 化炭化水素を総称してここでは八ロカーボンとする）に より，成層淃オゾン層が破填されつつあることが確突視 され，八ロカーボン類の生産・消費の規制に関する国際 的合意から，日本であ「特定物質の規制等によるオゾン 睥の保護に関する法律」が1989年から発効した。この問 題の解決の基本はその種の八ロカーボンの使用をなくす ことであり，規制も段階的にではあるがその方问を目指 している.てのような状況の中で，現実的な対㐫法の一 つとして, 吸着を朋いたハロカーボン回收法が注目され ている。すでに, 洗浄剤として用いられる一部のハロカ 一ボン類に対しては回収装置も市敗されており，そのほ とんよ゙に吸着剂として活性炭が利用されている。しかし， 現在広く使用されている多種類の八ロカーボン類に対す る活性炭の吸着特性は，まだ十分に把握されていない。 そこで今回，2種類の粒状活性炭に対する 4 種類の八口 カーボン, CFC -12, HCFC-22, CFC-114, halon-1301 の吸着平衡，および上記粒状活性炭を含めた計 5 種類の 活性炭に対するハロカーボンCFC - 12 の吸着平衡を測定 し, 吸着の基本特性について検討したのでその結果につ いて以下に報告する。

\section{1. 実 験 法}

\section{1 試料}

5 種類の供試活性炭 $\mathrm{A} \sim \mathrm{E}$ は沛販品をそのまま用いた。

† 1991年 5 月 2 日受理 ; 化学厂学会第54年会 (神户，1989年 4 月）にて一部発表

†† 570 守口市八雲中町 $3-15$
$\mathrm{A}, \mathrm{B}$ (白鷺 $\mathrm{G}_{2} \mathrm{X}$, 白鷺 $\mathrm{S}_{2} \mathrm{X}$, 武田薬品工業製), $\mathrm{C}(\mathrm{G}-$ $\mathrm{BAC} 70 \mathrm{R}$, 只羽化学工業製) は粒状であり,・D, E (A10, A 20, ユニチ力製) は繊維状である. その性状をTable 1 に示す.また 4 種類の八ロカーボン, ジクロロジフルオ ロメタン $\left(\mathrm{CCl}_{2} \mathrm{~F}_{2}\right.$, 以下 $\left.\mathrm{CFC}-12\right)$, クロロジフルオロメ タン $\left(\mathrm{CHClF}_{2}\right.$, 同 HCFC - 22), 1, 2-ジクロロ - 1, 1, 2, 2テトラフルオロエタン $\left(\mathrm{C}_{2} \mathrm{Cl}_{2} \mathrm{~F}_{4}\right.$, 同 $\left.\mathrm{CFC}-114\right)$, ブロ モトリフルオロメタン $\left(\mathrm{CBrF}_{3}\right.$, 同 halon-1301) 屯市貶 品をそのまま用いた。 その物性 ${ }^{2)}$ および成層圈オゾン破 壊係数 (ODP; Ozone Depletion Potential) $)^{7)}$ を Table 2 に併せて示す。 HCFC-22 を除く他の 3 物質は何れ屯規 制対象に指定されている。用いた八ロカーボンの純度は ガスクロマトグラフ（島津製作所製 GC-9A) の測定から, 何れも $99 \%$ 以上であるてとを確認した。

\section{2 測定装置および方法}

吸着平衡の測定には重量法を採用した。実験装置の概 略をFig. 1 に示す。スプリングバランスはステンレス (SUS 304) 製 (ば叔定数 $k=0.037 \mathrm{~g} \cdot \mathrm{mm}^{-1}$ ) を用いた。耐 压ガラス容器の中にスプリングバランスをセットし，そ の下部フックに試料である吸着剂を入れる石英製バスケ ットを吊り下げた。試料量は約 $1 \mathrm{~g}$ とした。 以上の系を 恒温槽中で一定温度 $(316 \mathrm{~K})$ に保ち吸着平衡の測定を行 った。温度は耐圧ガラス容器内に挿入した CC 熱電対 (JIS 0.4 級) で測定した。压力は $150 \mathrm{kPa}$ 以下はデジタル 庄力計 (横河電機製 TYPE 2654, 精度 $0.5 \% \mathrm{FS}$ ) で, それ 以上はブルドン管圧力ゲージ (SUS 316製, JIS 0.5 級)で 測定した。スプリングバランスの伸びは，カセトメータ (最小読取值 $1 / 100 \mathrm{~mm}$ ) で読み取った。読み取り值は吸 着質ごとに浮力補正を行った。また，測定前後における ば㸚定数の変化执よび吸着質のスプリングバランスへの

第18巻 第 1 号 (1992) 
Table 1 Characteristics of the activated carbons used in this work

\begin{tabular}{|c|c|c|c|c|c|}
\hline & $\mathrm{A}$ & $\mathrm{B}$ & $\mathrm{C}$ & $\mathrm{D}$ & $\mathrm{E}$ \\
\hline Form & pellet & pellet & sphere & fiber & fiber \\
\hline Surface area & & & & & \\
\hline$S \times 10^{-3}\left[\mathrm{~m}^{2} \cdot \mathrm{kg}^{-1}\right]$ & 1200 & 1250 & 1000 & 1000 & 2000 \\
\hline
\end{tabular}

Table 2 Physical properties of the halocarbons used in this work

\begin{tabular}{|c|c|c|c|c|c|}
\hline & & CFC-12 & $\mathrm{HCFC}-22$ & CFC- 114 & halon-1301 \\
\hline$M \times 10^{-3}$ & {$\left[\mathrm{~kg} \cdot \mathrm{mol}^{-1}\right]$} & 120.9 & 86.5 & 170.9 & 148.9 \\
\hline$T_{\mathrm{b}}$ & {$[\mathrm{K}]$} & 243.4 & 232.4 & 276.8 & 215.4 \\
\hline$T_{\mathrm{c}}$ & {$[\mathrm{K}]$} & 384.7 & 369.2 & 418.9 & 340.2 \\
\hline$p_{\mathrm{c}} \times 10^{-5}$ & {$[\mathrm{~Pa}]$} & 41.2 & 49.8 & 32.5 & 39.7 \\
\hline$b \times 10^{6}$ & {$\left[\mathrm{~m}^{3} \cdot \mathrm{mol}^{-1}\right]$} & 97.0 & 77.0 & 133.7 & 89.0 \\
\hline$O D P$ & {$[-]$} & $0.9-1.0$ & $0.04-0.06$ & $0.6-0.8$ & 10.0 \\
\hline
\end{tabular}
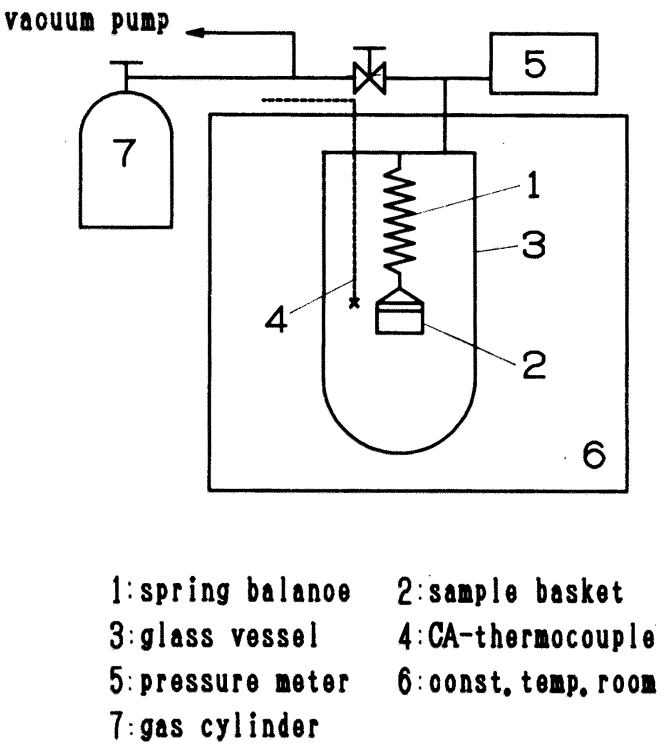

吸着が测定值に与える影響はいずれも無視できることを 確認した。これらのととから, 重量の測定精度は読取䛊 差も含め士 $1 \mathrm{mg}$ 以内と兒積られる. 測定に際しては, $373 \mathrm{~K}, 2$ 時間の真空脱気在行い吸着剂の前処理とした。

\section{2. 実験結果}

吸着質 CFC - 12, HCFC - 22, CFC-114, halon-1301に 対する活性炭 A, B の吸着平衡の測定結果を Figs. 2, 3 亿 示す。横軸は吸着質の相対圧力 $\left(p / p_{0}\right)$, 縦軸は吸着量 $\left(\mathrm{kg} \cdot \mathrm{kg}^{-1}\right)$ である、活性炭 $\mathrm{A}, \mathrm{B}$ ともに吸着等温線は類似 しており，いずれの吸着質屯相対化力の増加に対して吸 着量の立ち上がりが急であり, $p / p_{0}=0.1$ で最大吸着量 の $90 \%$ 以上.となる。同じくFig. 4 亿吸着質 CFC - 12 に対 する活性炭 C, D, E の吸着平衡の測定結果を示す。粒状 活性炭 Cを用いた系は上記活性炭 $\mathrm{A}, \mathrm{B}$ の系に類似して 立ち上がりが急であるが, 繊維状活性炭 D, Eを用いた系 は粒状活性炭に比較して立ち上がりが緩やかになってい る. いずれの系も王力の増加に従い吸着量は次第に飽和 に近づく、データは吸着質仕力の上昇方向 (吸着) につ いての测定值走す。逆方向（脱着）についての測定も 行ったが，測定した全ての系について吸脱着間のヒステ リシスは観察されなかった。

測定データの整理には, 活性炭を吸着剤とした吸着系 に対して従来よく用いられるDubinin-Astakhov 式 (以 下D-A 式 $)^{4)}$ を適用した。 D-A 式はEqs. (1),(2) でホ され, Eq. (1)はEq. (3) に変形される.

$$
\begin{aligned}
& W=W_{0} \exp \left\{-(A / E)^{n}\right\} \\
& q=W \rho^{*} \\
& \ln \ln \left(W_{0} / W\right)=n(\ln A-\ln E)
\end{aligned}
$$

$W$ は吸着質容積, $W_{0}$ は吸着空間の極限容積, $A$ は吸着
Fig. 1 Schematic diagram of experimental apparatus

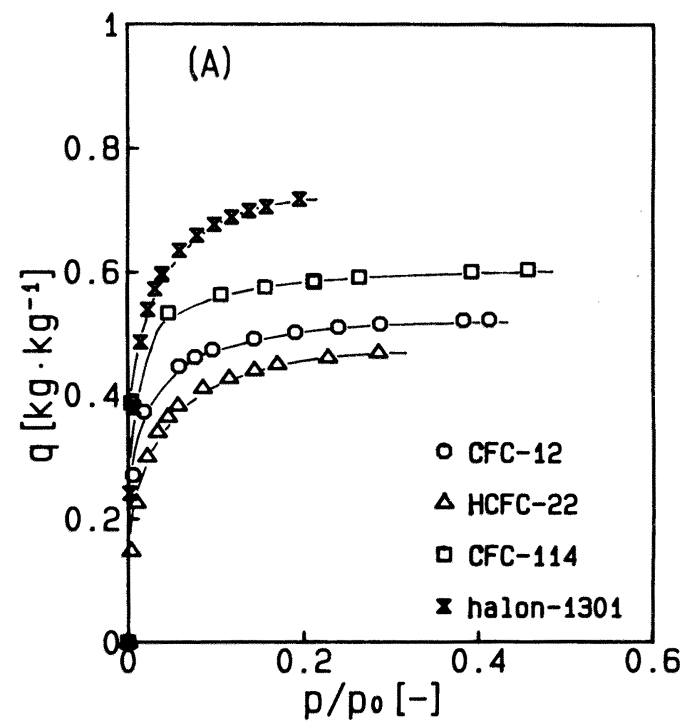

Fig. 2 Adsorption isotherms of CFC-12(O), HCFC-22 $(\triangle)$, CFC-114 $(\square)$ and halon-1301 $(\nabla)$ on the activated carbon $A$ at $316 \mathrm{~K}$. The curves were calculated by the D-A equation with the parameters shown in Table 3.

ポテンシャル $\left(=R T \ln \left(p_{0} / p\right)\right), E$ は特性エネルギー, $q$ は吸着量, $\rho$ *は吸着相密度である。吸着質の標準沸 点以上の温度で吸着させた場合, 吸着相密度はDubininNikolaev 式 ${ }^{1,3)}$ (以下D-N 式) から算出した值が良く適 合することが知られているので，今回屯それに従った。 D-N 式をEq. (4)にホす.

$$
\rho^{*}=\rho_{\mathrm{b}}-\frac{\rho_{\mathrm{b}}-\rho_{0}}{T_{\mathrm{c}}-T_{\mathrm{b}}}\left(T-T_{\mathrm{b}}\right)
$$




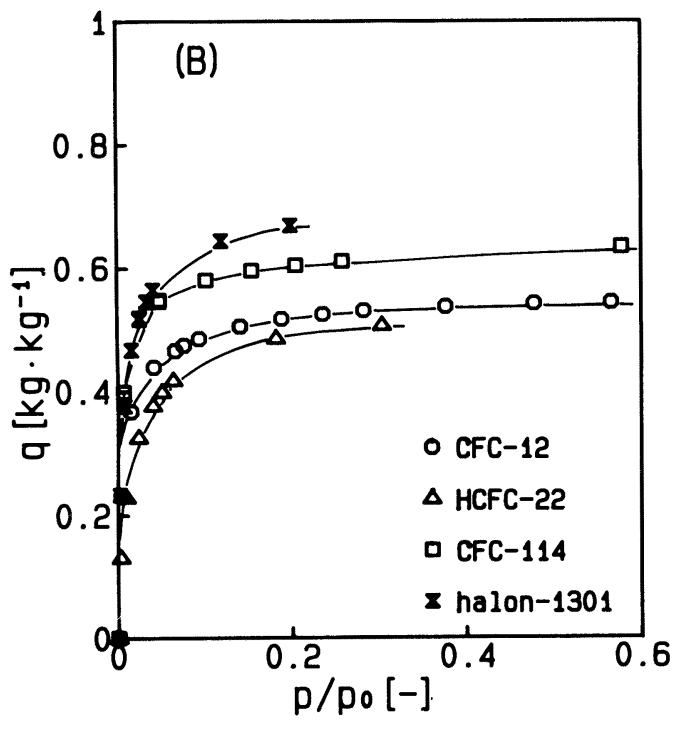

Fig. 3 Adsorption isotherms of CFC-12(O), HCFC-22 $(\triangle)$, CFC-114 $\square)$ and halon-1301 $(\nabla)$ on the activated carbon $B$ at $316 \mathrm{~K}$. The curves were calculated by the D-A equation with the parameters shown in Table 3 .

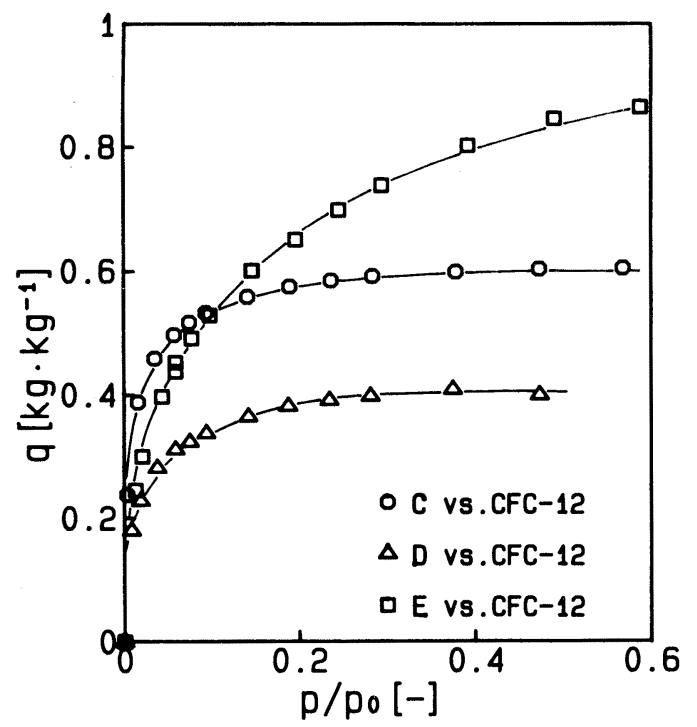

Fig. 4 Adsorption isotherms of CFC-12 on the activated carbons $\mathrm{C}(\bigcirc), \mathrm{D}(\triangle), \mathrm{E}(\square)$ at $316 \mathrm{~K}$. The curves were calculated by the D-A equation with the parameters shown in Table 3 .

$\rho$ は密度, $T$ は温度であり, 添字は $\mathrm{b} \cdots$ normal boiling point, $\mathrm{c} \cdots$ critical point での值を示し，また $\rho_{0}=M / b$, $b$ はvan $\operatorname{der}$ Waals の定数であり $b=R T_{\mathrm{c}} / 8 p_{\mathrm{c}}$ である.

まず各々の吸着系に関して $W_{0}$ を求めるため測定值の ln $W$ vs. $A^{n}$ プロットを行った。 その 1 例として活性炭 $\mathrm{B} \sim \mathrm{CFC}-12$ の吸着系についての結果を Fig. 5 に示す.

第18巻 第 1 号 (1992)
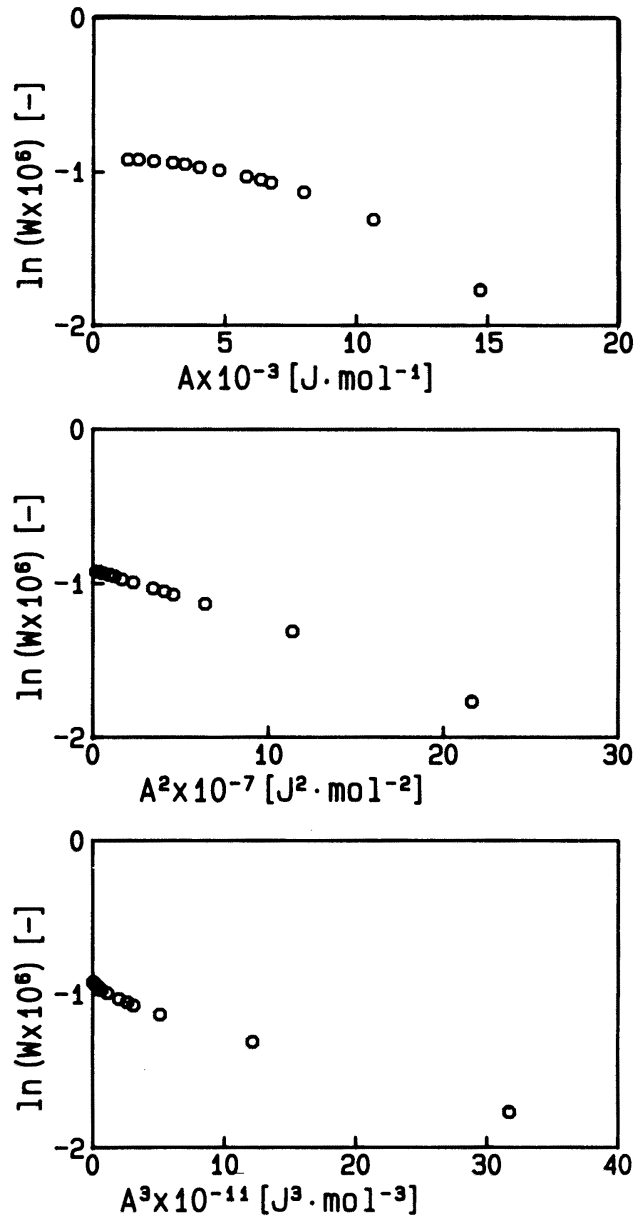

Fig. 5 Plot of $\ln W$ versus $A, A^{2}$ and $A^{3}$ for the CFC12 -activated carbon $\mathrm{B}$ system

Fig. 5 において $A^{1}$ および $A^{3}$ のプロットが湾曲している のに対し， $A^{2}$ のプロットがほぼ直線を示すことから，乙 の系については $n \fallingdotseq 2$ であり, Eqs. (1),(2)があてはま ることがわかる.そしてプロットの外挿から $W_{0}=0.407$ $\times 10^{-6} \mathrm{~m}^{3} \cdot \mathrm{kg}^{-1}$ が求められる. 同様にして各吸着系にお ける $W_{0}$ を $\ln W$ vs. $A^{n}$ プロットから順次求めた。

次に正確な $n$ および特性エネルギー $E$ を求めるため, 上記 $\ln W$ vs. $A^{n}$ プロットから得られた $W_{0}$ を用いて Eq. (3) に従い $\ln \ln \left(W_{0} / W\right)$ vs. $\ln A$ プロットを行った。 そ の 1 例として 4 種類のハロカーボンに対する活性炭 $\mathrm{A} の$ プロットをFig. 6 に示す. 得られたプロットは最小二乗 法により各々直線に近似し, その傾斜から $n$ を求め, 外 挿値から $E$ を求めた。 このとき, 最初の $W_{0}$ の決定には 外挿による䛊差が含まれる。 また，その $W_{0}$ を基に求め た $n, E$ も同様である. したがって, 得られた值は相互 に適正化する必要がある，乙のため，てこまでに得られ た $W_{0}, n, E$ の各值を初期值とし, Eqs. (1), (3)にしたが 


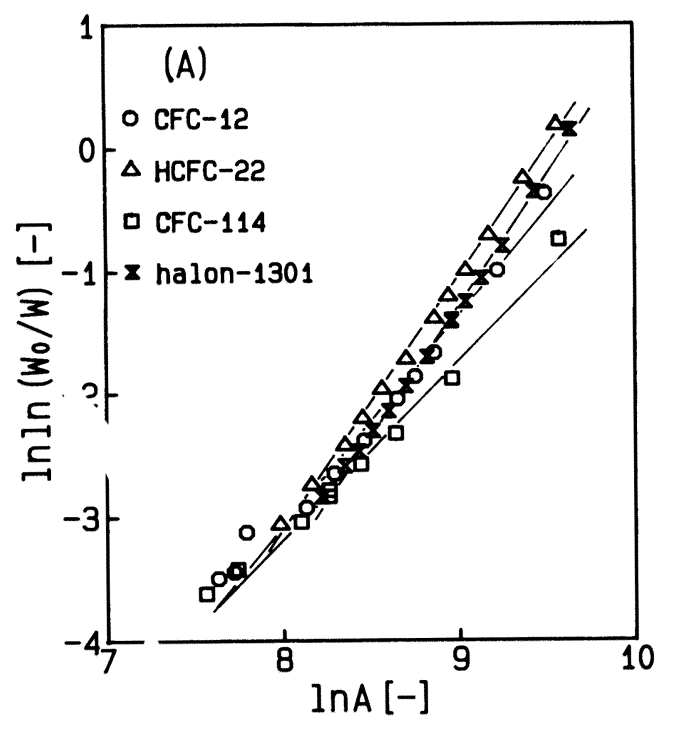

Fig. 6 Fit of the D-A equation (Eq. (3)) to experimental isotherms of CFC-12 $(\bigcirc)$, HCFC-22 $\triangle$, CFC- 114 $(\square)$ and halon-1301( $\nabla)$ on the activated carbon A at $316 \mathrm{~K}$

って収束計算を行った，最終的に得られたD-A 式の各 パラメータをTable 3 にまとめて示す.

$W_{0}$ および $n$ 値は活性炭 $\mathrm{A}, \mathrm{B}$ に対し，吸着質の種類に かかわらずそれぞれ $W_{0} \fallingdotseq 0.4 \times 10^{-6} \mathrm{~m}^{3} \cdot \mathrm{kg}^{-1}, n \fallingdotseq 2$ と ほぼ同じ值となった，活性炭 C, D てついてもそれに近

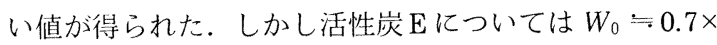
$10^{-6} \mathrm{~m}^{3} \cdot \mathrm{kg}^{-1}, n \fallingdotseq 1$ となった。 また $E$ の值は吸着質の 蒸発潜熱 $\Delta H_{0}$ との関係で $E=(n / 3) \Delta H_{0}$ となることが指摘 されている ${ }^{31}$ が, 本実験の場合むほぼその関係が満足さ れることがわかった。

測定した全吸着系について, Table 3 の各パラメータ 值を用いて Eqs. (1)〜 (4) に従い計算した吸着量は, Figs. $2 \sim 4$ に示すように, 広い拄力範囲においてマークで示 す測定值と良く一致し, 偏差は土 $2 \%$ 以内であった。乙 れは, D-A 式による活性炭一八ロカーボン吸着系の測 定值の整理が適切であることを示す.

\section{3. 考察}

\section{$3 \cdot 1 n$ 值について}

$\mathrm{D}$ - A 式を説明する基本的なモデルから， $n$ 值は吸着 剤の細孔径と吸着質の分子径との比と相関を有するとと が明らかにされている3゙. たとえば，カーボンブラック などの非多孔性材料，あるいはシリカゲルなどのマクロ 孔の発達した材料への吸着の場合は $n=1$, 通常のガス 吸着用活性炭への吸着では $n=2$, 超ミク口孔の発達し たゼオライト, 分子ふるいカーボンへの吸着では $n=3$
Table 3 Parameters for the halocarbon-activated carbon systems

\begin{tabular}{clccc} 
Adsorbent & Adsorbate & $\begin{array}{c}W_{0} \times 10^{3} \\
{\left[\mathrm{~m}^{3} \cdot \mathrm{kg}^{-1}\right]}\end{array}$ & $\begin{array}{c}n \\
{[-]}\end{array}$ & $\begin{array}{c}E \\
{\left[\mathrm{~kJ} \cdot \mathrm{mol}^{-1}\right]}\end{array}$ \\
$\ldots \ldots \ldots \ldots \ldots \ldots \ldots \ldots \ldots \ldots \ldots \ldots \ldots \ldots \ldots \ldots \ldots \ldots \ldots \ldots \ldots \ldots \ldots \ldots \ldots$ \\
A & CFC-12 & 0.338 & 2.13 & 16.1 \\
& HCFC-22 & 0.392 & 2.31 & 13.2 \\
& CFC-114 & 0.420 & 1.81 & 22.4 \\
& halon-1301 & 0.430 & 2.38 & 14.7 \\
B & CFC-12 & 0.402 & 2.02 & 16.8 \\
& HCFC-22 & 0.420 & 2.35 & 12.9 \\
& CFC-114 & 0.439 & 1.85 & 20.3 \\
& halon-1301 & 0.399 & 2.44 & 14.9 \\
C & CFC-12 & 0.447 & 2.22 & 14.9 \\
D & CFC-12 & 0.303 & 2.31 & 12.7 \\
E & CFC-12 & 0.690 & 1.29 & 8.8 \\
\hline
\end{tabular}

となり,$n$ 值は吸着分子の吸着によって失われた自由度 の数と見なせる. 活性炭 $A \sim D$ についてててで得られた $n$ 值は活性炭についての多くの既報値と一致する。しか し活性炭 $\mathrm{E}$ は $n$-1 となることから, 一般の活性炭に比 較してマク口孔を多く有する細孔構造を持つことが示唆 される。また得られた $n$ 值はみかけ上带小数となるが， これは珙なるnの吸着が共存するためと考えられてい $ろ^{3)}$. 細孔径分布 ( $n$ の共存) を考慮した D - A 式の一般 化屯試みられている きにはこの带小数の $n$ を朋いて差し支えないことも知ら れている ${ }^{3)}$. 事実本研究に扔いても，得られた带小数を 用いた計算結果と測定值とは良く一致した。乙のように D - A 式は，吸着質分子径亡吸着剂の細孔径との関係を 基本として成立しているので，阔一の吸着剤を用いて異 なる吸着質を吸着させた場合に，吸着質の分子径とD-A 式から得られた $n$ 值との間には何らかの相関関係がある 亡考えられる。活性炭 A, B について, 吸着質分子径亡 $n$ 值との関係を Fig. 7 に示した。乙こで分子(值)径 $d$ は van der Waals の先数 $b\left(=R T_{\mathrm{c}} / 8 p_{\mathrm{c}}\right)$ との関係式 Eq.

(5)から算出した.

$$
b=\frac{2}{3} \pi N d^{3}
$$

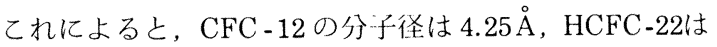
$3.94 \AA$, CFC-114 は $4.73 \AA$, halon-1301 は4.13 $\mathrm{A}$ となる. 活性炭 $\mathrm{A}, \mathrm{B}$ 岘者に打いて, 吸着質分子径 $d$ と $n$ 值との 間には比較的良い相関が見られ， $d$ の増大にしたがって $n$ は減少する傾向にある。 D-A 式の説明では吸着剂細 孔径 $D$ と吸着質 $d$ との比 $D / d$ が小さくなると $n$ 值は大 きくなるはずであるが，上記結果は逆であり一見䂆盾し ているようにみえる。しかしこれは，使用した活性炭が 細孔径分布を有するため異なる $n$ の吸着が共存し， $d$ が 大きくなると分子がミク口孔に浸入しにくくなり，相対 的にマクロ孔吸着の割合が增大して $n$ が小さくなってい 

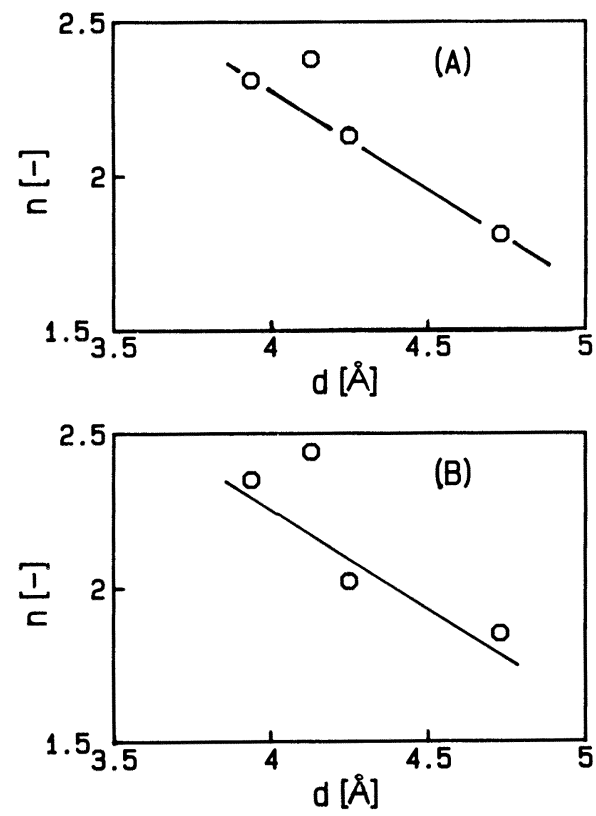

Fig. 7 Plot of the exponent $n$ of the D-A equation against the molecular diameter of the adsorbate $d$. Adsorbent: (A), activated carbon A ; $(\mathrm{B})$, activated carbon $\mathrm{B}$

ると考えられる、吸着剤が細孔径分布を有するとき， $d$ が大きくなるにしたがって吸着量分布が $D$ 大の方向に移 動するという結果は鈴木らの報告 ${ }^{6)}$ と一致する。また， halon-1301 は相関した值線からやや外扎 $n$ が大きな值と なる，乙の原因として，他の吸着質に比較して吸着相密 度が大きいことによる効果が考えられるが, 詳細は明ら かでない，以上の結果は， $n$ 值が吸着剂の細孔径と吸着 質の分子径との比に相関を有するという説 ${ }^{31}$ を寒付ける.

\section{$3.2 W_{0}$ について}

4 種類の異なる八ロカーボンに対する活性炭 $\mathrm{A}, \mathrm{B} の$ 吸 着では, 吸着究間の極限容積 $W_{0}$ が吸着質の種類にかか わらずほぼ近い値となる。このことから, 吸着相密度の 算出にD-N 式を適用したことが妥当であることがわか る。

\section{$3 \cdot 3 E$ について}

特性エネルギー $E$ の値は，吸着質分子の大きさを表す バラメータたとえばバラコールあるいは蒸発潜熱 $\Delta H_{0}$ と 相関があるととが報告されている! が，D－A 式は吸着 質分子径と吸着剤の細孔径との関係を基本としているの で，本報では直接 Eq. (5) から求めた吸着質分子径との 相関を試みた。分子ふるいカーボンと各種吸着質との関 係を調べた河添らの既報值 ${ }^{5)}$ を同じ方法で整理した結果 と併せて，活性炭 A, B を用いたときの結果をFig. 8に示 す. $E$ は吸着質分子径の増大にしたがって直線的に増大

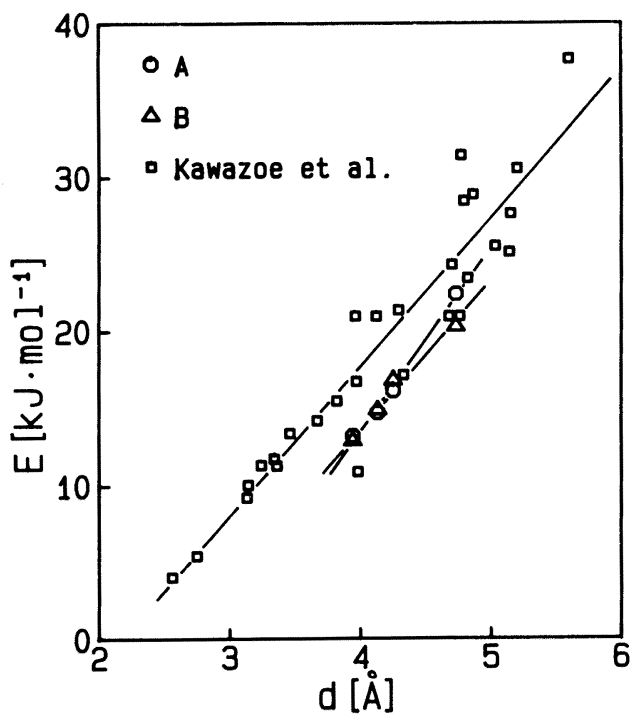

Fig. 8 Plot of the characteristic energy of adsorption $E$ against the molecular diameter of the adsorbate $d$. Adsorbent used: activated carbon $\mathrm{A}$ $(\bigcirc)$, activated carbon $\mathrm{B}(\triangle)$, carbon molecular sieve (Ref. 5) ( $\square$ )

し, 分子径 $d$ との間には良好な相関関係が認められる。 この結果から，同一吸着剂住して，Eの值は吸着質の 分子径から推算可能であることがわかる。また，既報の デー夕による直線と本報のデータによる直線とは重なら ないが，泪者の傾斜がほぼ一致することから，相関され た直線の傾き $(E / d$ 比) は吸着剂の種類で決定され, 切 片は吸着剂の性状（細孔径分布等）で決定されると推定 できる。

また, 活性炭 A, Bについて得られた各パラメータが近 い値を示すととから，雨者はきわめて類似した表面構造 を有すると考えられる.

結言

2 種類の粒状活性炭に対する 4 種類の八ロカーボン, CFC -12, HCFC - 22, CFC -114, halon-1301 の吸着平衡, および上記活性炭を含めた計 5 種類の活性炭に対する CFC-12 の吸着平衡を測定し, 吸着の基本特性を検討し た。その結果，次のことが明らかになった。

1）平衡の測定値はD-A 式にしたがって整理でき, 得られた同式の各パラメータを用いた計算値と測定值と は良く一致する。

2）吸着空間の極限容積 $W_{0}$ は, 吸着質の種類にかか わらず同一の吸着剂についてほぼ一定の値となる。

3）特性エネルギー $E$ 抢よび $n$ 值と吸着質分子径 $d$ 之 の間には，良好な相関関係が認められる。 
得られた D-A 式の各パラメータ, 吸着質の物性およ びこれらの相関関係は, これに類する吸着系の基本的な 性格を表していると考えられる. したがって, 他の八ロ カーボン類に対する吸着等温線の推算に活用できると同 時に, 回収装置に用いる吸着剂の選定, 吸着条件の設計 等に有効な基礎データとしても役立つものであると考え る.

\section{Nomenclature}
$A=$ decrease of free energy of adsorbed phase based on liquid phase $\quad\left[\mathrm{J} \cdot \mathrm{mol}^{-1}\right]$
$b=$ van der Waals constant
$d=$ molecular diameter $\left[\mathrm{m}^{3} \cdot \mathrm{mol}^{-1}\right]$
$E=$ characteristic energy of adsorption $\left[\mathrm{J} \cdot \mathrm{mol}^{-1}\right]$
$M=$ molecular weight
$N=$ Avogadro constant $\left[\mathrm{kg} \cdot \mathrm{mol}^{-1}\right]$
$n=$ exponent in Eq. (1)
$p=$ pressure in vapor phase
$p_{0}=$ saturated vapor pressure
$p_{\mathrm{c}}=$ critical pressure
$q$ = amount adsorbed

[kg-adsorbate $\cdot \mathrm{kg}^{-1}$-adsorbent ]

$$
\begin{aligned}
& R=\text { gas constant } \\
& S=\text { surface area }
\end{aligned}
$$

$$
\begin{array}{rrr}
T= & \text { temperature } & {[\mathrm{K}]} \\
T_{\mathrm{b}}= & \text { normal boiling point } & {[\mathrm{K}]} \\
T_{\mathrm{c}}= & \text { critical temperature } \\
W= & \text { filled volume of micropore adsorption } \\
& \text { space } & {\left[\mathrm{m}^{3} \cdot \mathrm{kg}^{-1}\right]} \\
W_{0}= & \text { limiting volume of micropore adsorption } \\
& \text { space } & {\left[\mathrm{m}^{3} \cdot \mathrm{kg}^{-1}\right]} \\
\rho^{*}= & \text { density of adsorbed phase } \\
\rho_{0}= & \text { density of adsorbed phase at critical } \\
& \text { temperature } \\
\rho_{\mathrm{b}}= & \text { density of liquid at normal boiling } \\
& & {\left[\mathrm{kg} \cdot \mathrm{m}^{-3}\right]} \\
&
\end{array}
$$

\section{Literature cited}

1) Dubinin, M.M.: Chem. Rev., 60, 235 (1860)

2) Japanese Association of Refrigeration: "Reito Kuucho Binran”, p.184 (1981)

3) Kawai, T.: Kagaku Kōgaku, 40, 393 (1976)

4) Kawazoe, K., V.A. Astakhov, T. Kawai and Y. Eguchi: ibid., 35, 1006 (1971)

5) Kawazoe, K., T. Kawai, Y. Eguchi and K. Itoga; J. Chem. Eng. Japan, 7, 158 (1974)

6) Suzuki, M and A. Sakoda: ibid., 15, 279 (1982)

7) Synthesis Report, UNEP/Ozl. Pro. WG. II(1)/4 (1989)

\title{
Adsorption Equilibria of Halocarbon Vapors on Activated Carbons
}

\author{
Takeshi Tomizawa, Yuko Nagakawa and Koji Arita
}

\section{Matsushita Electric Industrial Co., Ltd., Osaka 570}

Key Words : Adsorption, Adsorption Isotherm, Gas Phase, Activated Carbon, Halocarbon Vapor

Adsorption equilibria of four halocarbons, dichlorodifluoromethane $\left(\mathrm{CCl}_{2} \mathrm{~F}_{2}, \mathrm{CFC}\right.$ 12), chlorodifluoromethane $\left(\mathrm{CHClF}_{2}, \mathrm{HCFC}-22\right), 1,2$ - dichloro-1, 1, 2, 2- tetrafluoro ethane $\left(\mathrm{CClF}_{2} \mathrm{CClF}_{2}, \mathrm{CFC}-114\right)$, and bromotrifluoromethane $\left(\mathrm{CBrF}_{3}\right.$, halon-1301), on five activated carbons were measured at $316 \mathrm{~K}$ by the gravimetric method. The data obtained were correlated by use of the Dubinin-Astakhov equation ( $W=W_{0} \exp \{-(A)$ $\left.E)^{n}\right\}$ ) with the parameters of the adsorbents. The exponent $n$ ranged from 1.2 to 2.5 , depending on the adsorbate-adsorbent system, though the limiting volumes of micropore adsorption space $W_{0}$ of the adsorbent did not depend on the adsorbate. The characteristic energy of adsorption $E$ and the exponent $n$ were correlated by the molecular diameter $d$ of the adsorbate. 